\title{
El Movimiento por la Paz con Justicia y Dignidad
}

\author{
Elena Azaola
}

\begin{abstract}
No hay extensión más grande que esta herida, lloramos nuestra desventura y sus conjuntos y sentimos más la muerte que la vida.
\end{abstract}

Miguel Hernández ${ }^{1}$

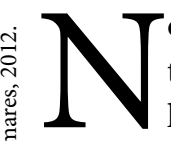
os ha parecido que un número de la revista Desacatos dedicado al análisis de la violencia en nuestro país no podía dejar fuera una de las respuestas ciudadanas más lúcidas y consistentes, que ha realizado un esfuerzo sin precedentes no sólo por hacer visibles y dar voz a las víctimas, como tantas veces nos lo han dicho, sino también por formular propuestas que permitan reducir la violencia y resarcir los daños que ésta ha dejado. Es por ello que en esta sección hemos querido dar la palabra a los dos líderes más destacados del Movimiento por la Paz con Justicia y Dignidad: Javier Sicilia y Emilio Álvarez Icaza. Pero antes de darles la

${ }^{1}$ Versos del poeta Miguel Hernández leídos por Javier Sicilia en la ceremonia de instalación de las mesas de trabajo con el Poder Ejecutivo el 21 de julio de 2011. palabra, quisiéramos recuperar para la memoria el trayecto que el Movimiento ha recorrido a poco más de un año de su creación. ${ }^{2}$

El Movimiento por la Paz con Justicia y Dignidad nació el 28 de marzo de 2011, luego de que Juan Francisco, hijo del poeta Javier Sicilia, y sus amigos Gabriel, Julio y Luis, fueran asesinados en Temixco, Morelos, con dos adultos que los acompañaban. A mi juicio, este gesto del poeta se ha convertido en uno de los principales rasgos y fortalezas del Movimiento. Me refiero a la decisión que lo dota de un contenido ético profundo: haber otorgado a la muerte de su hijo el mismo peso y el mismo significado que a todas las demás que han tenido lugar en circunstancias similares en nuestro país. Visto en retrospectiva, sorprende la rapidez con la que el Movimiento convocó - poco más de un mes después de los hechos citados- a una marcha en el Zócalo que tuvo lugar el 8 de mayo de 2011, en la que se anunció un Pacto Nacional. Ello pone de manifiesto que más allá de los

\footnotetext{
${ }^{2}$ Puede consultarse más información en la página electrónica: $<\mathrm{http}: / /$ movimientoporlapaz.mx/>.
}

The Movement for Peace, with Justice and Dignity

Elena Azaola: Centro de Investigaciones y Estudios Superiores en Antropología Social-Distrito Federal, México eazaola@ciesas.edu.mx

Desacatos, núm. 40, septiembre-diciembre 2012, pp. 159-170 
acontecimientos puntuales que desencadenaron la creación del Movimiento, las condiciones estaban dadas y había líderes que contaban con una idea clara de la situación del país y con propuestas de cómo debía enfrentarse lo que desde entonces no dudaron en calificar como una situación de "emergencia nacional". Igualmente elocuentes eran los mensajes que los ciudadanos portaban en mantas, carteles y cartulinas el 8 de mayo. Reproduzco algunos:

"Pedimos a los poderes en esta Marcha por la Paz y en silencio que callen por respeto y vergüenza", "No más balas: más cultura, más educación”, "Estamos cansados de engaños y mentiras", "Calderón: los niños no queremos jugar en tu guerrita", "Nuestros pasos son un camino de paz entre la masacre: vivos se los llevaron, vivos los queremos", "Más poesía, menos policía”, "Gracias, Sicilia, por sacar a mi espíritu del letargo: hoy el pueblo grita al unísono ¡No más sangre!”, “Sonora, autoridades: ¿dónde están nuestros hijos?", "Que nuestro silencio hable por ellos", "Ayúdanos a enviar 40 mil cartas de pésame", "Calderón: todos somos blancos colaterales", "Esta marcha es de hartazgo y de propuestas", "Que se vayan todos: PRI, PAN, PRD, PV y NA", “ $i N o$ están solos! Tenemos hambre de justicia, de paz, por la vida de todo México", "Más que los actos de los malos, me horroriza la indiferencia de los buenos", "Farsa, fracaso, Felipe: la violencia es el último recurso del incompetente", "Hasta la madre de la clase política: juntos, codo con codo, somos mucho más que PRI, PAN Y PRD", "Ni narcos ni militares, nosotros podemos, ciudadanos. Yo no me acostumbro a la violencia, ¿y tú?", "Para que la droga no llegue a tus hijos... Te los estamos matando" (registro de María Elena Barrié y Elena Azaola).

En el discurso que Javier Sicilia pronunció al llegar al Zócalo, acompañado de un grupo de víctimas provenientes de varios estados, señaló:

Estamos aquí para decirnos y decirles que este dolor del alma en los cuerpos no lo convertiremos en odio ni en más violencia, sino en una palanca que nos ayude a restaurar el amor, la paz, la justicia, la dignidad y la balbuciente democracia que estamos perdiendo.
Convocó a un pacto, al que caracterizó como:

\begin{abstract}
un compromiso fundamental de paz con justicia y dignidad, que le permita a la nación rehacer su suelo, un pacto en el que reconozcamos y asumamos nuestras diversas responsabilidades, un pacto que le permita a nuestros muchachos, a nuestras muchachas y a nuestros niños recuperar su presente y su futuro, para que dejen de ser las víctimas de esta guerra o el ejército de reserva de la delincuencia.
\end{abstract}

El Pacto Nacional que propuso el Movimiento el 8 de mayo contenía seis puntos: 1) verdad y justicia; 2) poner fin a la estrategia de guerra y asumir un enfoque de seguridad ciudadana; 3) combatir la corrupción y la impunidad; 4) combatir la raíz económica y las ganancias del crimen; 5) atención de emergencia a la juventud y acciones efectivas de recuperación del tejido social, y 6) democracia participativa y democratización en los medios de comunicación. Estas demandas fueron presentadas al presidente Felipe Calderón en la primera reunión de diálogo con el Poder Ejecutivo que tuvo lugar mes y medio después, el 23 de junio de 2011, en el Castillo de Chapultepec. Luego de casi cuatro meses, se celebró una segunda reunión, el 14 de octubre de 2011. Antes de cada encuentro hubo dos Caravanas: una hacia el norte en junio y otra hacia el sur en septiembre. El objetivo fue dar voz a las víctimas y acompañarlas en sus exigencias de justicia y reparación del daño.

El 21 de julio de 2011 se instalaron cuatro mesas de trabajo con el Poder Ejecutivo en el Museo Nacional de Antropología. Cada mesa contaría con representantes de ambas partes y se ocuparían de los siguientes temas: 1) gestión de justicia; 2) nuevo modelo nacional de relación, valoración y justicia a los derechos de las víctimas; 3 ) nuevo modelo de estrategia de seguridad que se oriente hacia los derechos humanos y a la paz, y 4) impulso de mecanismos de democracia participativa y democratización de los medios. Aunque el contenido de estas mesas se fue reformulando en las semanas siguientes, la realidad es que no obtuvieron los resultados deseados pues la 
gran mayoría de las propuestas formuladas por el Movimiento no fueron aceptadas por los representantes del Poder Ejecutivo. Poco después, de manera unilateral, el presidente de la República anunció la creación de la Procuraduría de Atención a Víctimas del Delito. El Movimiento consideró que ésta era una respuesta insuficiente e inapropiada, tanto por las escasas facultades de esta institución como porque no se le dotó de recursos.

El Informe que el Movimiento presentó a la Comisión Interamericana de Derechos Humanos en la audiencia "Seguridad Ciudadana y Derechos Humanos en México", realizada en Washington el 27 de octubre de 2011, reporta que en cada Caravana se documentaron violaciones a los derechos humanos. La Caravana del Norte recibió 291 testimonios de violaciones, $81 \%$ de las cuales ocurrieron después de junio de 2007: 53\% son desapariciones o secuestros y $45 \%$, homicidios. En $67 \%$ de los casos las víctimas no identifican al responsable de la violación. Sin embargo, en 13\% de los casos las víctimas creen que el responsable fue el Ejército y $8 \%$ señala como responsable a la policía. Las víctimas atribuyen al crimen organizado $4 \%$ de estas violaciones. En la Caravana del Sur se recibieron 221 testimonios, $52 \%$ fueron por desaparición forzada y $13.6 \%$ por homicidio.

En el Informe el Movimiento expresó que considera que hay tres temas interrelacionados: a) el desgarramiento del tejido social que amplios sectores están sufriendo como resultado del crimen organizado; b) la estrategia oficial enfocada principalmente en el combate por la vía armada, y c) la impunidad y la corrupción de instituciones de gobierno, así como de otros actores políticos. Es por ello, señalaron, que el Movimiento propone cambiar la estrategia de seguridad actual por una estrategia de seguridad humana y ciudadana. En el documento se asegura que ésta representa una ruta no sólo para contener la violencia, sino también para identificar las condiciones económicas, sociales y políticas subyacentes que la generan. Durante el primer año de acciones del Movimiento, tres de sus líderes fueron asesinados:
Nepomuceno Moreno, en Sonora, Pedro Leyva y Trinidad Cruz, ambos de Santa María Ostula, Michoacán. Destaca también que cuando el Movimiento inició se reconocían 40000 asesinatos relacionados con el combate al crimen organizado, y hasta abril de 2012 se habla de más de 55000 .

Además de los encuentros con el Poder Ejecutivo, el Movimiento había propuesto tener un diálogo con el Poder Legislativo y con los partidos políticos. Este último no ha tenido lugar, en cambio ha habido numerosas sesiones de trabajo con el Legislativo, aparte de la sesión en el Castillo de Chapultepec en septiembre de 2011. Cabe destacar que el Movimiento se pronunció contra la Iniciativa de Ley de Seguridad Nacional, que proponía legalizar y ampliar la participación del Ejército en labores de seguridad pública. Finalmente, la iniciativa no se aprobó. El Movimiento se opuso también a la aprobación del Código Federal de Procedimientos Penales, que contenía disposiciones violatorias a los derechos humanos y que tampoco se aprobó. Apoyó, sin embargo, las iniciativas para crear un auditor especial de las Policías Federales, la de Reforma Política, la Ley de Guarderías, la de Obligatoriedad del Estado para Impartir Educación Media Superior, así como las correspondientes para crear una Comisión de la Verdad y para incorporar a cinco consejeros ciudadanos al Consejo Nacional de Seguridad Pública. De éstas, se aprobaron la de Guarderías, la de Educación Media Superior y algunos puntos de la Reforma Política. La iniciativa para federalizar el delito de desaparición forzada tampoco prosperó. El Movimiento se opuso a las modificaciones de la Ley Orgánica del Poder Judicial, con las que se pretendía crear una especialización en justicia militar, que tampoco fue aprobada.

La ley en que el Movimiento tuvo mayor participación y en la que empeñó gran cantidad de esfuerzos durante varios meses de trabajo e innumerables reuniones con víctimas, especialistas y legisladores fue la Ley General de Víctimas, que logró ser aprobada por las dos cámaras el 30 de abril de 2012, último día del Periodo Ordinario de Sesiones. La Ley 
obliga a las autoridades de los tres ámbitos de gobierno y de los tres Poderes Constitucionales, pero también "a cualquier oficina, dependencia, organismo o institución pública o privada" a proporcionar ayuda, asistencia o reparación integral a las víctimas. La reparación integral "comprende las medidas de restitución, rehabilitación, compensación, satisfacción y garantías de no repetición, en sus dimensiones individual, colectiva, material, moral y simbólica”.

La Ley tiene por objeto no sólo reconocer y garantizar los derechos de las víctimas del delito, sino también de las violaciones a derechos humanos que establecen tanto la propia Ley, como la Constitución, los tratados internacionales de derechos humanos que el Estado mexicano ha suscrito, así como los demás instrumentos de defensa de los derechos humanos. Define a las víctimas directas como:

aquellas personas que directamente hayan sufrido algún daño o menoscabo económico, físico, mental, emocional, o en general cualquiera puesta en peligro o lesión a sus bienes jurídicos o derechos como consecuencia de la comisión de un delito o violaciones a sus derechos humanos.

Las víctimas indirectas son "los familiares o personas a cargo que tengan relación inmediata con la víctima directa y toda persona que de alguna forma sufra daño o peligre en su esfera de derechos por auxiliar a una víctima”. En su articulado precisa:

la calidad de víctima se adquiere con la acreditación del daño o menoscabo de los derechos en los términos establecidos en la presente ley, e independientemente de que se identifique, aprehenda, o condene al responsable del daño, o de su participación en algún procedimiento judicial o administrativo.

La Ley establece la creación de un Registro Nacional de Víctimas y de un Sistema Nacional de Atención a Víctimas y detalla la competencia y las responsabilidades de cada sector y autoridad. Enumera los derechos a la justicia, a la verdad, a la reparación integral y estipula medidas de atención, de protección y de asesoría jurídica por medio de una Defensoría de Víctimas. Dispone, entre otras, medidas de educación, económicas y de desarrollo, de rehabilitación, de compensación, de satisfacción y de no repetición. En síntesis, se trata de uno de los instrumentos legislativos más avanzados que existen hasta la fecha tanto en la legislación nacional como en la internacional. Resta que el Poder Ejecutivo la publique. No hacerlo, han dicho los líderes del Movimiento, sería un crimen. Quienes encabezan el Movimiento han subrayado que, contra lo que los más escépticos vaticinaron:

este logro ha sido resultado de dialogar con las instituciones y hacer propuestas concretas en diversos ámbitos gubernamentales así como [de] manifestarnos pacíficamente (Javier Sicilia, "El dolor que impulsa al Movimiento", en El Universal, 4 de mayo, 2012).

Destacaron que, si bien por sí misma la Ley no es suficiente para garantizar su cumplimiento, confían en que, así como la presencia de las víctimas, del Movimiento y de los especialistas fueron determinantes para la aprobación de la Ley, también lo podrían ser para su implementación (Emilio Álvarez Icaza, "Ley General de Víctimas: palabra cumplida", en El Universal, 4 de mayo, 2012).

\section{ENTREVISTA CON JAVIER SICILIA ${ }^{3}$}

Elena Azaola (EA): Quisiera saber algo sobre tus antecedentes: ¿Dónde naciste, en qué año y qué estudiaste? ¿Identificas a alguna persona que hubiera tenido una influencia especial en ti durante tu infancia? También

\footnotetext{
${ }^{3}$ Las entrevistas con Javier Sicilia y Emilio Álvarez Icaza fueron realizadas por Elena Azaola, quien las transcribió, editó y envió a los entrevistados para su revisión. Cabe destacar que los entrevistados dieron su aprobación para publicar este texto. Las entrevistas tuvieron lugar el 31 de enero de 2012 en las oficinas del Centro Nacional de Comunicación Social (Cencos).
} 


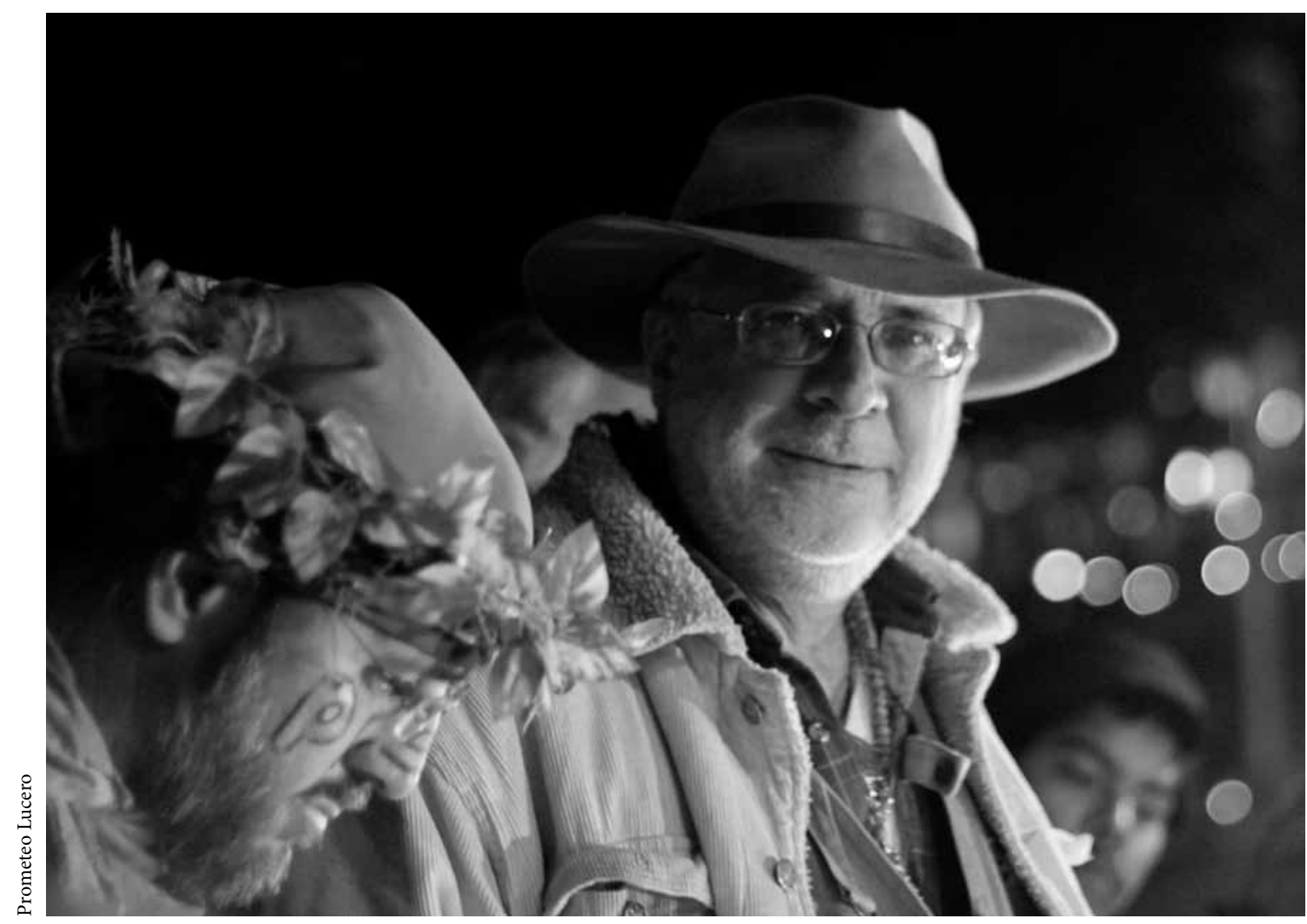

Javier Sicilia en el acto del Movimiento por la Paz con Justicia y Dignidad en el Ángel de la Independencia del Día de Muertos, 31 de octubre de 2011.

me gustaría saber cómo trazas tu origen como poeta, ¿qué te marcó o marcó tu vida para que eligieras la poesía?

Javier Sicilia (Js): Nací en la ciudad de México en 1956. Ingresé a la carrera de ciencias políticas en la Universidad Nacional Autónoma de México (UNAM), pero sólo cursé dos años. No aguanté la univocidad ni la racionalidad del discurso de la ciencia política, tampoco el excesivo marxismo que impregnaba todo en aquellos años. Me interesaba la historia del pensamiento político, pero no vista a través de una sola ideología. Me fui a estudiar letras francesas, porque mi vocación es de poeta, porque en la literatura encuentro todo: desde la vida espiritual hasta el psicoanálisis, la historia, la sociología, la antropología, en fin, todo. Es un género tan despreciado el de la literatura, pero tan rico: es conocer al hombre, pues. Yo escribía poesía desde antes. Crecí con la poesía porque mi padre era un poeta y un cristiano muy profundo. Aunque nos mantuvo con su actividad en las ventas en el terreno textil, en realidad era un poeta, aunque no le interesaba publicar. Grabó un disco con su poesía para la familia y cuando murió reuní sus poemas y los publiqué en un libro. Nací oyendo poesía y el Evangelio, siempre en ambientes religiosos. Desde que estaba en la escuela quería escribir poesía, pero los poetas que me leía mi padre eran aplastantes: después de leerlos, no me atrevía a escribir. En la prepa, que cursé con los Hermanos del Espíritu Santo, en el Instituto de Humanidades y Ciencias (Inhumiyc), me encontré con Tomás Calvillo y Fabio Morábito. Con ellos 
empecé a escribir poesía. Luego me fui a vivir a los cinturones de miseria en una comunidad jesuita. Estaba muy indeciso, quería ser sacerdote, pero no me dejaron, iy qué bueno!, porque lo de la obediencia no se me da. En ese momento no sabía si estudiar filosofía o ciencia política. Me incliné por la ciencia política y después por la literatura.

EA: Sería un lugar común decir que seguramente no te imaginabas desempeñando el papel que hoy desempeñas como líder de un movimiento social. Sin embargo, curiosamente, parecías muy bien equipado, muy bien preparado para ello. ¿Qué te llevó a asumir una posición así, más allá de tu terrible tragedia personal?

Js: Creo que uno se prepara para lo que no sabe. Siempre he tenido una inmensa pasión por la filosofía política y por la vida espiritual. Para mí un personaje fundamental ha sido Gandhi, al que conocí por mi madre. Ella era una inmensa admiradora de Gandhi. El pensamiento de Gandhi me llevó a quien fundó una comunidad en Francia y entendió la vida evangélica incrustada en la vida política de la sociedad contemporánea. Vida espiritual que se inserta en el acontecer político. Ahí están dos fuentes de lo que llamo prepararse para lo que uno no sabe. Uno los hace parte de su vida sin saber. Miraba también lo que era la realidad a través de Iván Illich. Tuve una amistad muy profunda con él. Es la vida espiritual llevada a la vida política. Todos ellos vienen de una tradición espiritual pero que saben articular dentro del hoy moderno. Creo que eso me formó y también las experiencias que compartía con varios de mis amigos, como Tomás Calvillo, Pietro Ameglio y Rafael Landerreche. Este último se quedó a vivir en comunidades indígenas de Chiapas y fue quien formó a López Obrador en la acción no violenta siguiendo la tradición de Gandhi. En mí reconozco la influencia de Gandhi, Iván Illich, Lanza del Vasto y la de los místicos San Juan de la Cruz, Sor Juana Inés de la Cruz y Santa Teresa de Jesús. También la del budismo zen. Para mí se trata

de tomar el Evangelio y a Cristo en serio para analizarlos, pues creo que la excesiva tradición teológica nos impide ver la actuación política de Cristo, de ese Dios encarnado que tiene que ver con la vida de su tiempo. A fin de cuentas, hay que tener presente que él es asesinado y juzgado por motivos políticos.

EA: Cuéntame un poco de lo que encontraste en tu camino en las Caravanas hacia el norte y sur del país. ¿Qué es lo que más te impactó? ¿Te sorprendió lo que encontraste o hasta cierto punto lo esperabas?

Js: No imaginaba, no sabía lo que se había convocado. Vine a la ciudad de México con la bandera a caminar y dispuesto a caminar solo. No imaginaba lo que se había despertado. Recuerdo que incluso Carmen Aristegui me preguntó ese día si vendría solo. Le dije que sí, pues es un asunto de dignidad, de moral, de respeto a las víctimas. Si hubiera ido solo, eso no le resta nada a la verdad. La verdad es la verdad, así vaya uno o vayan cien mil. Ya había criticado la política gubernamental porque me parecía espeluznante que se estuviera criminalizando a los muertos. Me parecía un gesto indigno de un cristiano, como lo es el presidente, no preocuparse por los muertos o considerarlos "daños colaterales". Si hay un crimen de lesa humanidad por el que deba responder el presidente Calderón es ése: negarles su condición humana a los muertos. Muy pocos se habían atrevido hasta entonces a nombrar a los muertos, a devolverles su rostro, su nombre, su historia, porque aun los que sean culpables, tenemos que saber quiénes son y de dónde vienen. La violencia viene muchas veces del olvido, de la negación, del desprecio. Y que le nieguen la dignidad a la gente que ha muerto, como si fuera una cucaracha, es inadmisible. Lo que me sorprendió de las marchas fue el dolor pero, sobre todo, la capacidad para hacer con él amor, compasión. Me sorprendió encontrarme con una gran reserva moral a pesar del dolor y de los agravios. Eso es lo que encontré: una gran solidaridad a pesar de que el Estado ha humillado y sigue humillando a los criminales. Esa solidaridad da algo - no dejo de pensar como poeta—, ¡da luz! Si en el más absoluto desierto, como es 
este país, puede surgir, puede despuntar aunque sea una sola hoja, uno sabe que ahí hay vida.

La fiesta que más me gusta es la Navidad, es la misa de la luz que surge en medio de la noche, que es una metáfora de lo que es o de lo que puede ser el nuevo día a pesar del horror que seguimos viviendo. Es la vela que se enciende a mitad de la noche, un punto de luz que nos dice que hay algo más en medio de las tinieblas. Lo hermoso es que cuando se recuerde esta época oscura, se recordará que, en medio de la noche, hubo hombres y mujeres buenos.

No me hago ilusiones en contra de ciertos mesianismos históricos, como los de los teólogos de la liberación. Creo que el reino son momentos que surgen de las fracturas de la historia y que es ese "ya, pero aún no" donde está el amor, está el reino, está la democracia. En esa hoja que despunta en el desierto está el reino, pero no plenamente. Es la historia de los hombres frente a la imbecilidad humana que hace que haya hombres, que recuperemos cosas buenas para la humanidad. No hay que cejar en esa esperanza de que el mundo puede ser mejor. Si uno ve esa larga lucha que emprendió Gandhi, no debe olvidar que tardaron 40 años en echar a los ingleses y eso sigue siendo un punto de referencia, un punto de luz. Sin él y sin la gente buena que sale a dar la cara por la humanidad, estaríamos solos. Estaríamos solos sin esa reserva moral. Es lo humano que se expresa contra el Estado y contra el crimen. Porque ¿qué es el crimen si no la pura instrumentalización de la economía para maximizar las ganancias? Sin esa reserva moral que cuestiona ese modelo estaríamos perdidos, como lo estamos cuando el hombre bajo ese modelo es visto como "recurso humano", la tierra como "recurso natural explotable". De ahí a utilizar a la gente para secuestrarla, para explotarla o para prostituirla, hay sólo un paso más.

EA: ¿Cuál es tu propio balance de los aciertos, las fallas y los retos que tiene por delante el Movimiento?

Js: El acierto fue reunir esa reserva moral del país y colocar en la agenda la situación de emergencia en que hoy vive el país. También el diálogo que ejercimos, aunque nos lo critiquen desde todos lados, creo que fue un acierto ejercer el diálogo. Se han logrado pocas cosas. Una es la Procuraduría y otra que está en proceso es la Ley de Víctimas. Algunos me dicen que tener una Ley de Víctimas significa que las leyes no se han aplicado y es cierto, pero la Procuraduría es importante para que ejerza lo que la ley manda. También ha sido un acierto reunir a otros que estaban separados y hacer crecer la conciencia ciudadana, humana. Otro acierto ha sido el discurso, haber roto el discurso político hegemónico, vaciado de contenido, unilateral.

La debilidad del Movimiento es que nació de la intuición y ahora necesita una organización más clara. También que somos un movimiento pobre, no tenemos dinero, nuestras capacidades logísticas son pobres. No hemos podido evitar que nos maten o secuestren gente. No hemos podido empujar la defensa legal de las víctimas. También ha sido difícil acordar agendas porque hay demasiados dolores, aunque esto es parte de la búsqueda de darle organicidad a lo que ya tiene rostro.

En cuanto a los retos, si bien la reserva moral es grande, el poder de las armas es inmediato y sus consecuencias son atroces. Sin esa reserva moral, sin esa gente, el país ya no existiría porque construir, mantener y hacer crecer cuesta mucho, mientras que destruir es muy fácil. El mal es más fuerte. Sin embargo, el Movimiento ha hecho ver que la reserva moral es enorme porque las víctimas no odian. $\mathrm{Si}$ nos atuviéramos al gobierno, el país ya no existiría. A veces los politólogos piensan al Estado con sus teorías y por eso me preguntan y no entienden por qué igualo a los criminales con el Estado. El "haiga sido como haiga sido" fue un mensaje de índole delincuencial, y así se lo dije al presidente, o el hecho de que alguien pueda trasladar 25 millones de pesos en efectivo es también delincuencial. Si tuvieran tantita dignidad, deberían haber renunciado. $\mathrm{Y}$ cuando dicen que el gobierno está combatiendo la criminalidad, les he dicho que si el crimen funciona es porque desde dentro hay quien lo apoya. 
EA: $Y$ frente al panorama de instituciones incapaces para ofrecer justicia y respuestas a las víctimas, ¿visualizas algún otro escenario posible donde ellos puedan recuperar la paz y la dignidad? ¿Hay otras alternativas o habrá que seguir acudiendo a las instituciones?

Js: Cuando me dicen que los diálogos no van a servir, les he dicho, tanto a los zapatistas como a los de Morena, que lo que ellos no entienden es que somos un movimiento de víctimas. La gente quiere justicia y hay que estar encima de las autoridades, exhibirlas, no podemos prescindir de ellas, pero el hecho de darle consuelo le permite a la gente vivir con su dolor y ésa es ya una forma de justicia.

Creo que lo que nos está tocando vivir en nuestro tiempo es un parteaguas parecido a la caída del Imperio Romano. Si hacemos reconstrucción histórica, el Estado hobbesiano, en sus muchas variantes, que ha acompañado a la economía capitalista y se ha ido desmoronando, ha dejado un Estado corrupto, vulnerado, y de esas grietas es de donde surgen movibalbuceamos algo nuevo, ya lo han hecho antes los zapatistas. Quizás estemos dirigiéndonos hacia formas globales, pero confederadas de gobiernos locales. Los zapatistas fueron respaldados desde muchos lados. O quizás vayamos al sueño de Gandhi, que también tenía que ver con comunidades confederadas, en una economía pobre como la de la India, donde visualizaba a un millón de aldeas con una economía local. Quizás estemos yendo a ésas o a otras formas de organización como las que también plantean los kurdos en Turquía o los indígenas en Bolivia. Tenemos que reinventar un nuevo mundo porque el Estado y la economía actuales están en crisis. O puede que se trate de un Estado en mutación, como diría Tomás Calvillo. Pero mientras esto se acaba de desmoronar, no podemos prescindir del Estado $\mathrm{y}$ tenemos que asegurarnos de que cumpla. Los ciudadanos tenemos que ir a votar en blanco a las urnas porque, como es evidente, las víctimas son seres humanos. Gandhi decía que si un gobierno existe es porque lo apoyan los ciudadanos. En cambio, si una

sociedad entera no acude a las urnas, no apoya a ese Estado. Pero no hay esa conciencia en los ciudadanos y a las elecciones se les llama "democracia". Mientras tanto, el poder militar continúa creciendo, no obstante que es un desorden del alma, de la libertad. Pero mientras sigamos sosteniendo al Estado, ahí están y estarán sus instituciones podridas extorsionándonos. Y todavía vamos a ir a las urnas a legitimar sus gastos de campaña. Tenemos hoy 250000 desplazados en el país e ir a las urnas es sostener eso. Hay que dejar de cooperar con el Estado para que el Estado se transforme. Tenemos que exigir, presionar, por dignidad.

\section{ENTREVISTA CON EMILIO ÁLVAREZ ICAZA}

Elena Azaola (EA): ¿En dónde naciste? ¿En qué año? ¿Qué estudiaste?

Emilio Álvarez Icaza (EAI): Nací en la ciudad de México el 31 de marzo de 1965. Soy sociólogo por la UNAM y luego estudié una maestría en ciencias sociales en la Facultad Latinoamericana de Ciencias Sociales (Flacso). Actualmente estudio el doctorado en ciencias políticas en la UNAM e hice un diplomado en derechos humanos en la Universidad Iberoamericana.

EA: ¿Qué acontecimientos consideras que han tenido una influencia decisiva en tu trayectoria?

EAI: Me marca mucho mi contexto familiar y el momento que vivió mi familia. Fui el 12 de 14 hijos y me toca un momento de la evolución de mis padres en que asumen una agenda social como opción de vida. Mi padre era ingeniero civil, pero en los años cincuenta fundó el Movimiento Familiar Cristiano y a mediados de los sesenta mis padres van al Concilio Vaticano Segundo. Ese acontecimiento cambiará a mis padres y a mi familia, que por entonces fundan Cencos. Comenzó siendo una organización de comunicación del Episcopado católico y terminó siendo una asociación civil. Mientras que la organización dejó el trabajo eclesial y asumió el trabajo social, mi familia dejó de ser una 
familia de clase media alta y pasó a ser de clase media baja. Fui muy influenciado por el catolicismo social que, en México, fue muy cercano a la teología de la liberación. Hice mi primera comunión con Sergio Méndez Arceo y en casa de mi padre me tocó conocer a mucha gente, a muchas víctimas de la represión, a refugiados y a luchadores sociales. Tenía 12 años cuando la policía allanó Cencos. La UNAM estaba en huelga y la policía entró tanto a Ciudad Universitaria como a Cencos. Se llevaron todo: gente, equipo, documentos, y entonces decidieron trasladar las oficinas a nuestra casa. De niño supe lo que era todo eso: nos amenazaron, intentaron secuestrarnos. Entré a trabajar a Cencos como mensajero: diario me echaba 52 kilómetros en bici, repartiendo mensajes. Ya en el Colegio de Ciencias y Humanidades ( $\mathrm{CCH}$ ) se perfila más claramente mi vocación social. Empiezo el activismo dentro del trabajo eclesial de base y luego decido estudiar sociología. Aunque ya era analista, decido dejar Cencos para dedicarme a estudiar. Al terminar la maestría decido regresar a Cencos. Había hecho un viaje desde Londres hasta Katmandú y recuerdo que estando ahí les escribí a mis padres para decirles que había decidido regresar a Cencos y convertirlo en parte de mi plan de vida.

A través de mi padre yo había conocido a líderes sociales y políticos, a obispos. Conocí a Granados Chapa, Heberto Castillo, Julio Scherer, Samuel Ruiz, Méndez Arceo. Ya después, siendo un director muy joven de Cencos, estuve también cerca de Sergio Aguayo y Mariclaire Acosta. Ahí fue cuando conocí a mi esposa. Viene entonces el fraude electoral del 88 y en los noventa surge un activismo civil muy fuerte. Mi padre opta por la participación partidista a través del Partido de la Revolución Democrática (PRD) y yo decido participar por la vía de la sociedad civil. Participé en Alianza Cívica como observador electoral, luego fui consejero electoral del Distrito Federal y después presidente de la Comisión de Derechos Humanos del Distrito Federal. Fui muy joven en todos estos procesos: cuando entré a la Comisión tenía 36 años. En resumen, vengo primero de un proceso de formación familiar, luego tengo una trayectoria académica que he mantenido de manera paralela dando clases durante todos estos años y luego viene mi participación en el proceso de ciudadanización que tuvo lugar en los años ochenta y noventa.

EA: A diferencia de las víctimas, en tu caso ha habido una elección personal para sumarte al Movimiento por la Paz. ¿Cómo te explicas esta decisión en función de tu trayectoria?

EAI: Parte de mi apuesta de vida ha sido acompañar casos y causas. Me dedicaba desde Cencos a organizar conferencias de prensa de casos muy delicados. Ya entonces acompañaba a víctimas, tarea que continué en la Comisión de Derechos Humanos. Hay una clara opción personal. Participo en el Movimiento coadyuvando a la atención a las víctimas, tendiendo puentes con actores gubernamentales. Sin embargo, no me imaginaba a mí mismo en un movimiento de esta naturaleza. Aún hace un año, no hubiera creído encontrarme aquí.

EA: Del balance que recientemente ha efectuado el Movimiento, ¿cuál es tu conclusión acerca de los principales aciertos del Movimiento?

EAI: El principal acierto ha sido dar voz a las víctimas porque las humaniza y coloca el tema en el debate público. También porque genera un cuestionamiento al gobierno y a la propia sociedad y logra, desde el aporte ético de la no violencia, conmover al país y dar testimonio del dolor. Ayuda a dar voz a las víctimas que no la tienen, que no tienen contactos, especialmente a las más pobres, que son las víctimas a las que el gobierno no les toma ni la llamada. Éste es el acierto más importante. Tiene por detrás una pedagogía ciudadana que apuesta al diálogo, a la inclusión, en un país en que el diálogo no es una práctica. Se apuesta al diálogo desde la ética y en defensa del Estado democrático de derecho.

EA: ¿Cuál es tu conclusión sobre el momento actual que vive el Movimiento? ¿Qué ha fallado y cuáles son los retos que habrá que enfrentar en el futuro inmediato? 
EAI: Las debilidades tienen que ver con la naturaleza del Movimiento, que en su nombre marca una aspiración muy amplia: la paz con justicia y dignidad, en el que muchos actores se ven reflejados, por lo que el Movimiento cataliza mucho del descontento social. Pero el Movimiento no surge en una lógica electoral ni de poder o de cuotas, y en el proceso de encontrar su identidad y de ir empatando expectativas sucede un ejercicio muy complejo, no libre de tensiones. Su fortaleza, que es la libertad, es también, en cierta medida, su debilidad, pues carece de recursos y no acepta recursos públicos. La debilidad tiene que ver también con articular los esfuerzos que se llevan a cabo en 26 ciudades y la dificultad de los actores de entender los mensajes y los códigos que no son fácilmente entendidos por todos. Los códigos del poeta, del amor y de la compasión, son difíciles de entender para algunos. Recibimos críticas tanto de la izquierda como de la derecha porque no acaban de entender que la agenda del Movimiento son las víctimas que tradicionalmente han sido instrumentalizadas por el poder o por otros. El Movimiento se mueve en otra esfera, en otra dimensión.

Los desafíos tienen que ver con avanzar en hacer un movimiento con procesos horizontales, sin convertirlo en una organización, pero que tenga mejores formas de coordinar sus actividades, de acompañar a las víctimas, de logística y operación y de transmitir mejor su mensaje. Ahora el Movimiento no tiene la misma cobertura que antes, hay un cerco informativo que también tiene que ver con que el Movimiento se sumó a la crítica por la concentración en los medios. Otro desafío es dialogar con procesos que tienen lugar más allá del país, en América Latina, por ejemplo, porque el problema no es sólo de este

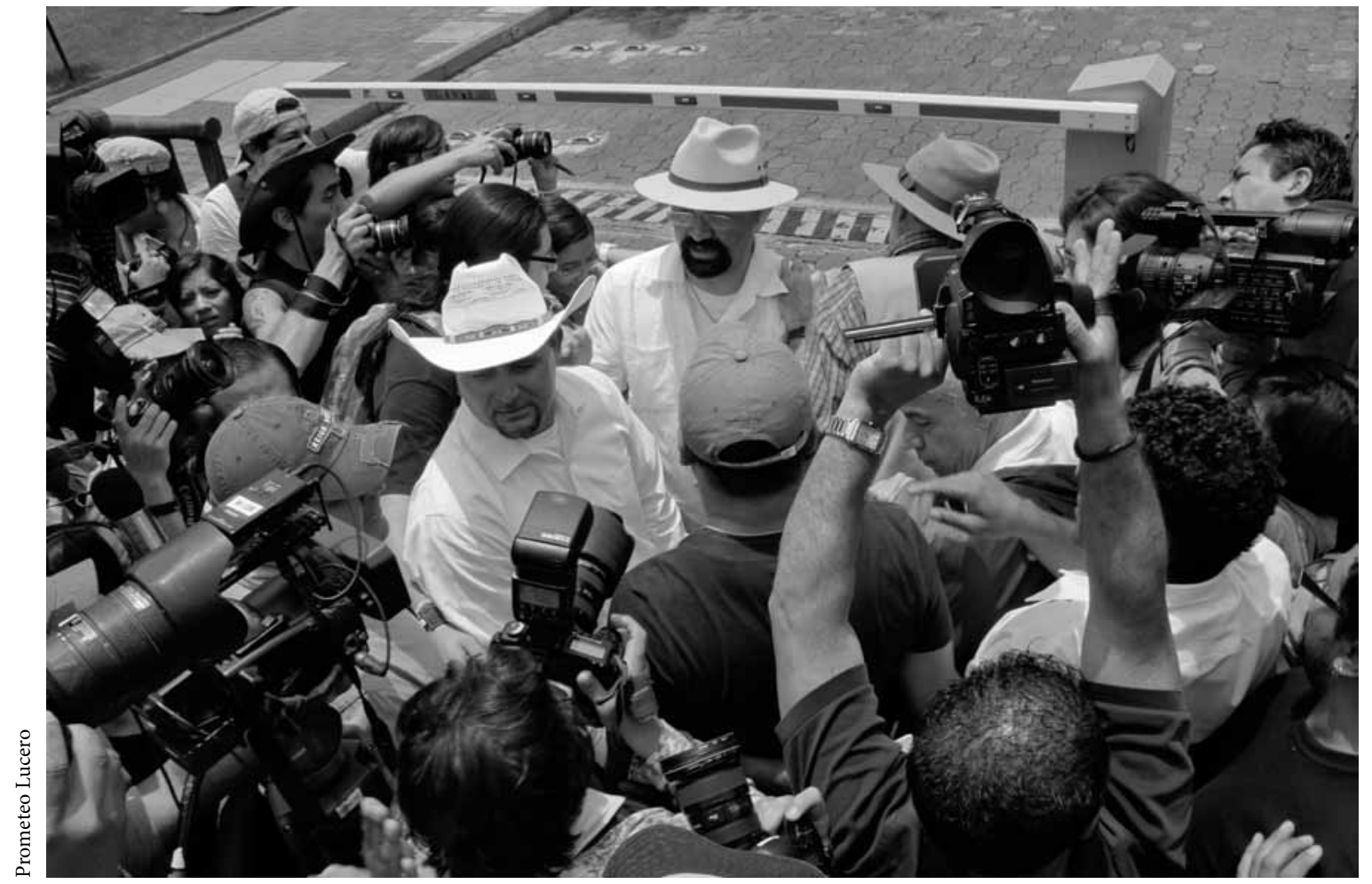

Emilio Álvarez Icaza en la marcha del Movimiento por la Paz con Justicia y Dignidad del Museo de Antropología a Los Pinos y al Senado de la República, 14 de agosto de 2011. 
país y podemos recuperar experiencias que ayuden a acelerar los procesos en México.

EA: De los recorridos que hicieron por el país, ¿cómo describirías la situación que encontraron? ¿Qué es lo que más te preocupa?

EAI: Lo que más me sorprendió, me conmovió, fue el nivel de abandono, el desastre y la lejanía por parte de los gobiernos. Al emprender la Caravana no pensamos que la situación estuviera tan mal, pero el recorrido ha permitido visibilizar a los muertos, a los desaparecidos, a los desplazados. Al empezar el Movimiento se reconocían 30000 muertos, ahora tenemos 60000 . Hasta cambió la narrativa del presidente, que ahora ya se refiere al dolor. La Caravana del Norte fue para mí un antes y un después: nunca había llorado tanto en mi vida. Simultáneamente me impresionó la esperanza que se generaba porque pensaba que si las víctimas tenían esperanza, México tenía esperanza. El avance del control por parte de las estructuras del crimen es impresionante. Luego vimos que el sur también está podrido por el nivel de desapego y de lejanía por parte de los gobiernos. Me quedo muy preocupado por las instituciones de justicia y por la penetración de la delincuencia en las instituciones de seguridad y de justicia.

Lo que me queda claro es que sus normas son autorreferenciales y es necesario que entiendan la situación de las víctimas. Esto es parte del proceso pedagógico del Movimiento: el hacer ver que hay otra forma de hacer las cosas y de organizar el mundo. El evento de ayer, ${ }^{4}$ en el que las víctimas agradecen por el lugar que se les da y por la posibilidad de hacer oír su voz, así lo muestra. No es que con ello se solucione su situación, pero siempre es más ligero cargar entre varios y compartir el dolor que hacerlo a solas. Es hacerlo más llevadero y tener más elementos para trabajar ese dolor. La justicia es muy lenta y hoy por hoy lo que podemos hacer es acompañarlos.

\footnotetext{
${ }^{4}$ Se refiere a la puesta en escena de "En los zapatos del otro", organizada por un grupo de artistas en nombre del Movimiento por la Paz con Justicia y Dignidad, que tuvo lugar en el Teatro de la Ciudad de México el 30 de enero de 2012.
}

EA: Frente al panorama real de la incapacidad o la falta de voluntad de las instituciones para hacer justicia a las víctimas, ¿visualizas algún otro escenario o crees que deberían seguir yendo una y otra vez a las instituciones?

EAI: Es como una sociedad empujando a un enorme elefante que no se quiere mover. La lucha por la justicia en México requiere de mucha tolerancia a la frustración. Por eso lo que hemos tratado de hacer es el diálogo social y el diálogo político, que son los dos pies del Movimiento. No podemos sustituir ni a las Policías ni a los Ministerios Públicos. Hay muchos que desde dentro trabajan para impedir la justicia. Son criminales o cómplices de los criminales, como lo muestra el caso de Nepomuceno: los que se llevaron a su hijo eran policías. También los que se llevaron al muchacho de Monterrey eran policías, y cuando éstos están a punto de ser detenidos, sus compañeros les pasan el pitazo y resulta que nunca regresan a trabajar. No nos queda más que seguir luchando y exigiendo para que esto no les pase a otros, para que no haya otros que tengan que llorar a sus hijos. No podemos perder la esperanza, por lo menos hay que ponerles presión. Ése fue el error de la transición: pensar que los partidos iban a hacer el cambio. El cambio tiene que venir de la sociedad y el gran cuello de botella es la justicia. El camino es la solidaridad y el desarrollo de las capacidades y las habilidades de las víctimas. La pregunta que hizo Julián Le Barón es muy valiosa. Él dice que tenemos que dejar de preguntarnos dónde están las instituciones o dónde están las autoridades porque la pregunta es dónde estamos nosotros, los ciudadanos, que permitimos que todo esto pase.

Lo veo como cuando en la lucha contra el fraude electoral pensábamos que era muy difícil cambiar las cosas. Luego nos dimos cuenta de que era una cultura hegemónica y que todos teníamos que hacer el cambio, no solamente el gobierno. La verdad es como un corcho: siempre flota cuando se le quita la presión que lo sumerge. Con el tiempo empezará a emerger la verdad y vamos a saber la magnitud de los daños que este gobierno ha ocasionado. La 
Caravana que pensamos hacer en Estados Unidos tiene que ver con que el problema no se puede resolver sólo desde aquí, necesitamos aliados. Cuando salimos a la primera Caravana, nunca pensamos tener el impacto que hemos tenido. Hay que hacer ver a Estados Unidos que nosotros no somos el problema y que están asociando erróneamente a los cárteles con el terrorismo. Nuestra causa obliga a desempeñar una función de alarma, de contracorriente, de profeta, aunque sabemos que los profetas nunca han sido populares. Hablar, como lo hacemos, de ética y de no violencia es lo más antipopular que existe y los discursos que se construyen para deslegitimar al Movimiento son de todo tipo e incluyen a los de la industria de la guerra y de las armas, a quienes no les conviene detener la violencia. Hay un manejo de la política de seguridad que es corrupto en el sentido humano y ésa es la fuerza del Movimiento, denunciar eso y tener la capacidad de asociarse, de vincularse con los expertos. El Movimiento es una especie de catalizador porque las causas que le dieron origen ya estaban ahí. El Movimiento ha demostrado la falsedad de algunos discursos y ha arrojado luz porque la fuerza ética de las víctimas es indiscutible y es arrolladora. Hay movimientos que se están organizando por todo el país y todo es a base de voluntad, de amor, de entrega. No nos queda de otra más que construir juntos, no podemos imponer una sola visión porque las realidades son muy distintas y si el Movimiento pretende tener un alcance nacional, tenemos que dar el espacio para que esas realidades se reflejen.

Soy optimista porque ya lo que hagamos es ganancia. La realidad es abrumadora pero lo que logremos es bueno y por poco que sea es mejor que no hacer nada. Veo mucho dolor, mucha desesperación, pero ese dolor está creando liderazgos nuevos que no estarían en esto si el Movimiento no les hubiera dado voz. La diferencia del Movimiento es que, cuando hicimos la Caravana, el objetivo no fue llenar las plazas o mostrar el músculo a nadie. La fuerza del Movimiento es la ética, es la construcción de esperanza. Hay mucha gente que no se une o que no se unió a la Caravana porque tiene miedo. Lo entiendo, lo vivo con calma, con optimismo y eso me ayuda a tener la paciencia para construir. Tenemos que tomar en cuenta que hay necesidades distintas, culturas distintas, tradiciones y formas de organización distintas, y que es a partir de dialogar y escuchar nuestras diferencias que podremos construir algo juntos. 